\title{
ANALISA SEPATU MODEL UNITED YANG MIRING DENGAN METODE PDCA UNTUK MENINGKATKAN KUALITAS DI PT. PRATAMA ABADI INDUSTRI
}

\author{
Ismi Mashabai \\ Dosen Teknik Industri Universitas Pamulang \\ ismimashabai17@gmail.com
}

\begin{abstract}
Di era globalisasi saat ini, persaingan di dunia bisnis sangat ketat dan berkembang pesat terutama di dunia bisnis manufaktur. Produk yang banyak keluhan dari pelanggan akan mengurangi nilai jual. Masalah kualitas dari VOC (Voice Of Costumer) setiap bulan direkap dan isu yang dominan akan meningkat. Sejalan dengan keluhan dari pelanggan, metode PDCA menjadi alat untuk peningkatan kualitas. Metode PDCA terbukti dengan penggunaan 5 mengapa dapat menemukan akar masalah dan menemukan penyebab potensial. Metode PDCA sangat membantu dalam memecahkan masalah dan memfasilitasi kualitas. Potensi penyebab teflon sering miring sepatu, perbaikan dilakukan pada "operator mesin teflon menjahit kerah seperempat" yang awalnya terbuat dari besi dan diganti dengan acrilic yang dikunci secara permanen.

Kata kunci: Kualitas peningkatan, VOC (Voice Of Costumer), Metode PDCA.
\end{abstract}

\section{I.PENDAHULUAN}

Di era globalisasi ini, banyak perusahaan berlomba-lomba menghasilkan produk-produk yang paling bagus dan memiliki kualitas yang tinggi. Selain itu banyak perusahaan yang menjual produknya yang bermutu dengan harga yang terjangkau. Dan ditunjang dengan kemajuan teknologi yang modern dalam proses produksi, sehingga menjadikan persaingan bisnis yang sangat ketat. Semakin tinggi tingkat persaingan akan menjadikan pelanggan menghadapi lebih banyak alternatif produk, harga dan kualitas yang bervariasi. Pelanggan akan selalu mencari nilai yang dianggap paling tinggi dari beberapa produk. Dan pelanggan akan menjadi produsen untuk produk yang memiliki banyak nilai tambah. Perusahaan harus bisa menggunakan data masa lalu dari sebuah variabel atau kumpulan variabel untuk dapat mengestimasi nilainya dimasa yang akan datang. Pada dasarnya, tujuan utama perusahaan adalah memperoleh laba yang optimal sesuai dengan pertumbuhan perusahaan dan biaya yang dikeluarkan untuk produksi. Hal-hal Pendukung proses produksi dalam sistem produksi dalam industri manufaktur sangat penting. Dengan tersedianya alat-alat pendukung dalam produksi dapat di pastikan inoutput dapat berjalan sesuai dengan perencanaan produksi. Terjadinya masalah kualitas pada produk sangat mengganggu dan dapat memberhentikan produksi, selain itu akan mengakibatkan kepuasan pelanggan pada perusahaan akan menurun. Kepercayaan yang sudah dibangun begitu lama akan runtuh dan perusahaan akan terancam mengalami kerugian yang besar. Agar masalah kualitas pada produk dapat segera diselesaikan, maka langkah awal yang di lakukan adalah gemba dan kemudian membuat PDCA. Metode ini sudah dilakukan di PT. Pratama Abadi Industri dan konsisten implementasikan hingga saat ini.

\section{DASAR TEORI}

\section{A, Konsep Dasar PDCA}

PDCA adalah singkatan dari PLAN, DO, CHECK dan ACT yaitu siklus peningkatan proses (Process Improvement) yang berkesinambungan atau secara terus menerus seperti lingkaran yang tidak ada akhirnya. Konsep siklus PDCA (Plan, Do, Check dan Act) ini pertama kali diperkenalkan oleh seorang ahli manajemen kualitas dari Amerika Serikat yang bernama Dr. William Edwards Deming. 


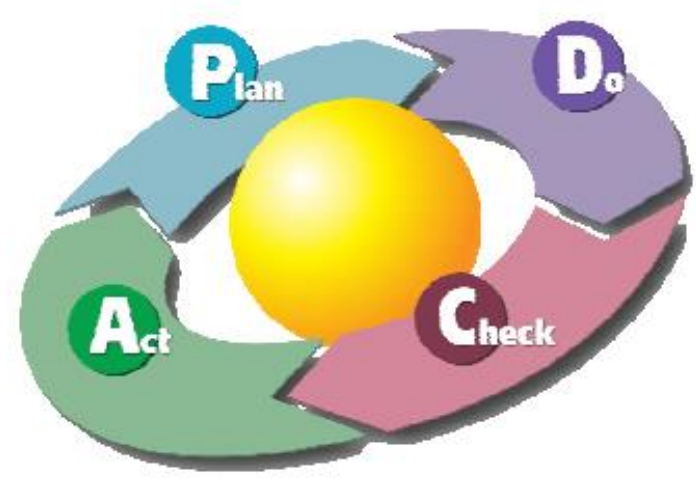

Gambar 2.1 Konsep PDCA

\section{B. Definisi VOC (Voice of Customer)}

VoC adalah istilah yang digunakan dalam dunia bisnis yang digunakan untuk menjabarkan proses yang mendalam yang bertujuan untuk mengetahui dan memahami ekspektasi, preferensi, dan ketidaksukaan pelanggan atas barang atau jasa yang ditawarkan. Sebenarnya Voice of Customer adalah bagian dari teknik riset pasar (market research) yang menyajikan laporan mengenai keinginan dan kebutuhan pelanggan yang tertata dalam struktur yang hirarkis. Poin-poin yang ada pada laporan kemudian disusun berdasarkan prioritas (sesuai dengan tingkat kepentingannya bagi pelanggan dan perusahaan).

\section{METODE DAN TEKNIK PENGUKURAN}

Penelitian ini dilakukan di PT Pratama Abadi Industri, yang beralamat di Jl. Raya Serpong km 7 Paku Alam, Serpong Utara, kota Tangerang Selatan, Banten 15325, Indonesia. Telepon (021) 5396140. Fax (021) 5396141. Sumber data penelitian ini adalah: 1) Dari hasil kuesioner yang disebarkan kepada konsumen disetiap pengiriman produk keluar negeri (eksport) secara berkala (nov 2013 s/d Apr 2014)

Populasi dan sampel penelitian ini adalah konsumen sepatu nike di luar negeri sebanyak 350 orang dalam 6 periode selama 6 bulan yakni pada bulan November 2013 sampai dengan bulan April 2014

Pengumpulan dan pengolahan data penelitian tugas akhir ini adalah pengumpulan data-data yang didapat kemudian di olah, penulis dapatkan dari bagian IDC (Indonesian development center). Dari data yang diperoleh, diolah untuk mendapatkan hasil VOC (Voice of costumer)

Teknik pengumpulan data dengan menggunakan metode pengolahan data history selama 6 bulan yang telah didokumentasi oleh perusahaan. Data penelitian ini diperoleh melalui wawancara dan data skunder dari bagian IDC (Indonesian development center). Data yang sudah didapat kemudian dikumpulkan dengan menggunakan metode non participant observation yaitu dengan mencatat (mengcopy) data yang terdokumentasikan di PT Pratama Abadi Industri.

Untuk teknik pengolahan data dilakukan dengan menggunakan metode PDCA (Plan Do Check Action).

1. Langkah Pertama adalah Plan:

a. Nama yang membuat PDCA

b. Jabatan yang membuat PDCA

c. Membuat tema

d. Mengisi kolom diperiksa dan tanggal

e. Mengisi kolom permasalahan (standar

f. perusahaan, situasi saat ini, perbedaan,

g. sejak kapan terjadi, dan dampak)

h. Mengisi kolom target/tujuan (apa, dimana, berapa, dan kapan)

i. Mengisi kolom analisis penyebab (mesin, manusia, metode, material, lingkungan)

j. Mengisi kolom penyebab potensial, pemeriksaan dan hasil

k. Mengisi kolom penyebab paling potensial ( 5 why)

1. Mengisi kolom akar penyebab

m. Mengisi kolom solusi (jangka pendek,jangka panjang dan mengapa direkomendasikan)

2. Langkah kedua adalah Do: Mengisi kolom implementasi (apa, siapa, kapan, dimana, status)

3. Langkah ketiga adalah Check: Mengisi kolom tindak lanjut (metode pemeriksaan, frekuensi pemeriksaan, dan siapa yang memeriksa)

4. Langkah keempat adalah Action : Mengisi kolom tindak lanjut yang disarankan

\section{HASIL DAN PEMBAHASAN}

Dari hasil kuesioner yang telah disebarkan kepada konsumen, dan dibuat rekapitulasinya maka didapat permasalahan kualitas sebesar $2,50 \%$ dari 360 suara konsumen dan yang dominan yaitu sepatu miring dengan model 
sepatu United. Contoh sepatu miring model United seperti gamba berikut :

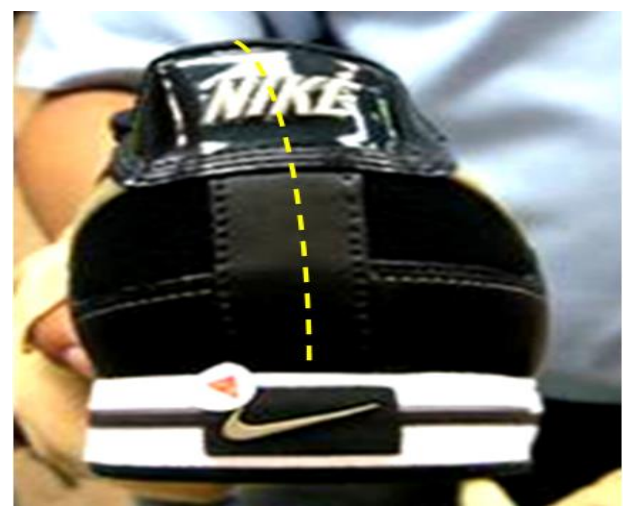

Sumber: PT Pratama Abadi Industri Jika terjadi komplain dari costumer maka akan merugikan perusahaan. Dampak yang fatal dari komplain costumer adalah dikembalikannya sepatu yang sudah dieksport, dan pengembalian dengan jumlah besar. Hal tersebut sangat merugikan perusahaan, oleh karena itu perusahaan berusaha semaksimal mungkin agar hal tersebut tidak terjadi, dan dari VOC (Voice Of Costumer) yang didapat maka permasalah kualitas yang paling dominan segera dilakukan Improvement. PDCA adalah alat yang digunakan dalam mencari akar permasalahan dan membuat improvement kualitas sehingga hal yang sama tidak terjadi kembali. Kemudahan-kemudahan dari PDCA sangat membantu proses improvement yang dilakukan. Denga Peran serta para team kaizen dan operator produksi menjadi tonggak improvement dilakukan secara konsisten dan terus-menerus. PDCA dan fish bone yang telah dibuat berdasarkan VOC (Voice Of Costumer) dominan yaitu "sepatu miring".

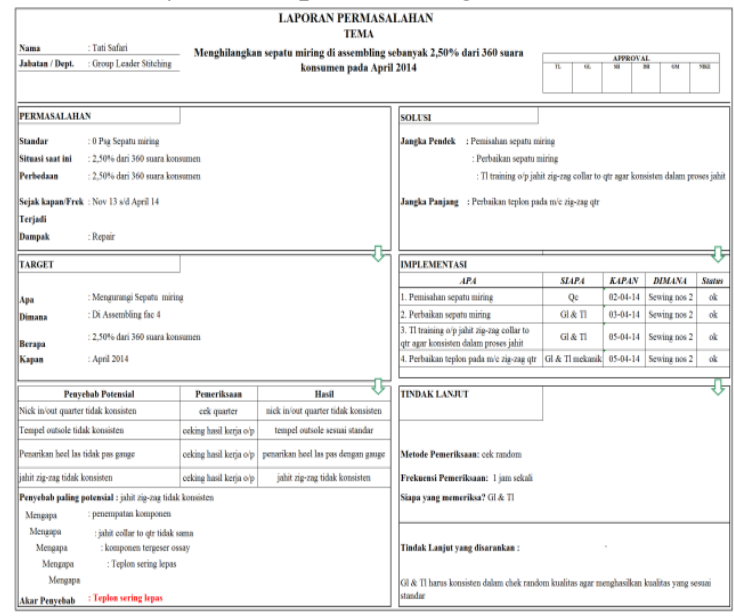

Sumber: PT Pratama Abadi Industri

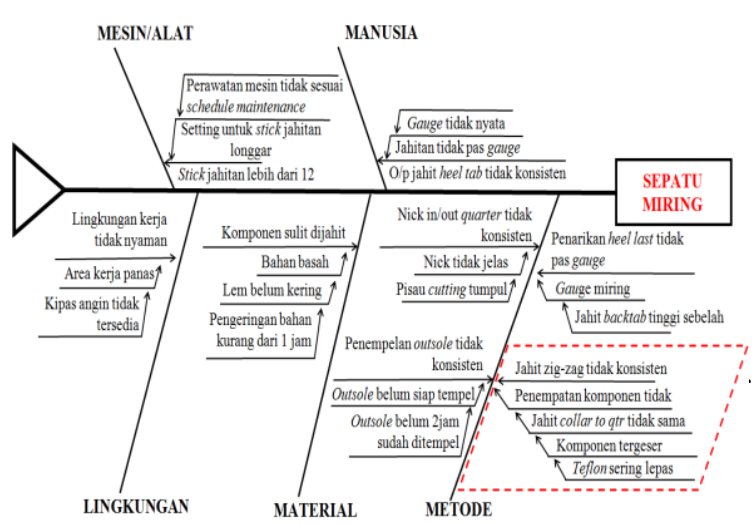

Sumber: PT Pratama Abadi Industri

sebelum membuat PDCA oleh semua pihak yang bersangkutan, maka didapatkan akar masalah yang mengakibatkan sepatu miring. Yakni "Teflon dimesin jahit sering lepas pada proses jahit collar to quarter" dan mengakibatkan komponen yang dijahit bergeser. Setelah pembuatan PDCA dari masalah kualitas, langkah selanjutnya adalah melakukan perbaikan kualitas diproduksi. Dengan dibantu oleh semua bagian, Perbaikan kualitas dilakukan dengan beberapa tahap, yaitu.

1. Memisahkan sepatu miring dari sepatu yang $a$ grade dengan dibantu oleh team inspection quality.

2. Memperbaiki teflon dimesin operator jahit oleh mekanik stitching. Dengan mengganti teflon semua proses jahit collar to quarter yang semula berbahan acrilic menjadi besi dan dikunci secara permanen.

3. Melakukan training kepada operator jahit collar to quarter agar konsisten dalam proses jahit.

4. Melakukan perbaikan sepatu miring oleh operator dengan pengawasan penuh dari team leader selama perbaikan.

5. Melakukan pengecekan atas perbaikan yang dilakukan dibantu oleh group leader proses stitching, dengan melakukan cek random 2 pasang komponen dari 12 pasang komponen jahit collar to quarter.

Dengan perbaikan yang sudah dilakukan diproduksi terbukti perbaikan kualitas dengan koordinasi yang baik antara bagian satu ke bagian lain dapat meningkatkan kualitas produk perusahaan. Untuk foto perbaikan kualitas yang dilakukan diproduksi, perusahaan hanya memperbolehkan 2 foto saja yang ditampilkan yaitu pembuatan PDCA dan training operator 
jahit collar to quarter saja. Perbaikan kualitas yang dilakukan seperti pada gambar berikut :
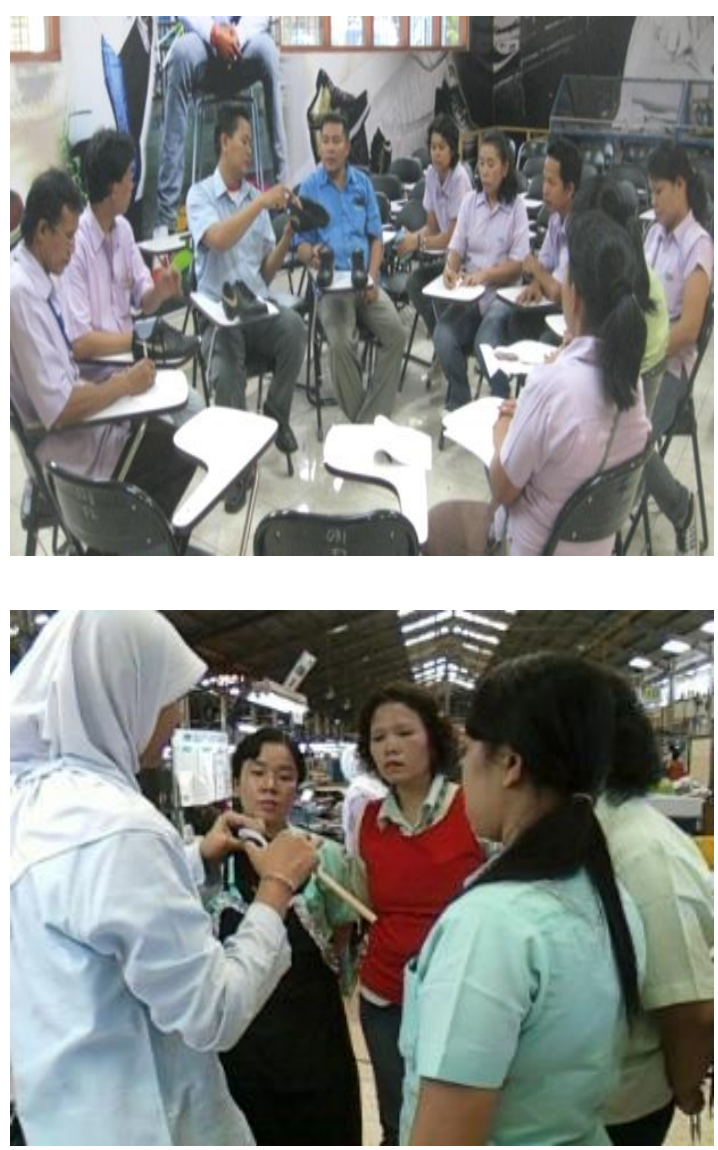

Sumber: PT Pratama Abadi Industri

Perbaikan kualitas akan membuat proses dan sistem industri menjadi lebih baik, produktifitas meningkat dan ineffisiensi (pemborosan) akan berkurang sehingga biaya per unit menurun. Pelanggan yang memperoleh produk berkualitas tinggi dengan harga yang kompetitif akan menjadi media promosi dan akan meningkatkan pangsa pasar. Dan dengan manajemen secara simultan berhasil mengurangi pemborosan terus meneruskan akan menghasilkan biaya kualitas menurun. Dapat meningkatkan kepuasan pelanggan secara terus menerus akan menghasilkan keuntungan yang diperoleh menjadi lebih baik.

\section{KESIMPULAN}

\section{A. Kesimpulan}

Berdasarkan pada penelitian yang telah dilakukan di PT. Pratama Abadi Industri. Maka penelitian ini dapat disimpulkan sebagai berikut:

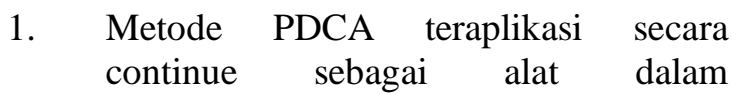

menyelesaikan masalah kualitas untuk mencari penyebab paling potensial dan akar penyebab.

2. Perbaikan yang dilakukan berdasarkan hasil analisis dengan Metode PDCA yaitu dengan dilakukannya solusi jangka panjang dan pendek, implementasi diproses produksi dan pengecekan secara random.

\section{B.Saran}

Mengacu pada penelitian yang telah dilakukan selama ini, penulis dapat memberikan saran-saran yang sekiranya dapat bermanfaat bagi kesempurnaan penelitian ini dan penulis, antara lain sebagai berikut:

1. Data yang diperoleh dari perusahaan, sebaiknya merupakan data primer. Karena melalui data primer, penelitian yang akan dilakukan akan lebih baik hasil yang nantinya akan diperoleh. Data primer didapatkan secara langsung setelah terjun di lapangan kerja produksi, atau dengan kata lain, peneliti akan melihat secara langsung proses produksi yang sedang berjalan hingga akhirnya akan mendapati kejadian proses produksi produk yang cacat/reject dan dapat diketahui denga jelas penyebabnya .

2. Metode PDCA yang digunakan dalam mencari akar permasalahan kualitas tidak hanya digunakan dalam mencari permasalahan kualitas namun dapat digunakan juga sebagai tools/alat untuk dapat meningkatkan kualitas produk secara berkelelanjutan/continue.

\section{DAFTAR PUSTAKA}

J, Supranto, Prof,M.A.,Apu,Pengukuran Tingkat Kepuasan Pelanggan Untuk Menaikkan Pangsa Pasar cetakan keempat.Jakarta: 2011

Perpustakaan Universitas Pamulang Hadi, Wibowo, 2008080049, Analisis Pengendalian Kualitas Produk Dalam Upaya Menanggulangi Kecacatan Produk Roti Donat Dipabrik Roti Naufal Donat Dengan Metode Six Sigma skripsi.Pamulang: 2012

Perpustakaan Universitas Pamulang Dorothea, Wahyu, Ariani, Dr, Mnajemen Kualitas Edisi 1. Jakarta: 2008

Zulian, Yamit, Drs, M.Si, Manajemen Kualitas Produk dan Jasa Cetakan Keenam. Yogyakarta: 2013J, Supranto, 
Prof,M.A.,Apu,Pengukuran Tingkat Kepuasan Pelanggan Untuk Menaikkan Pangsa Pasar cetakan keempat.Jakarta: 2011

http://qualitysystem.wordpress.com/2007/08/ 22voice-of-costumer-suara-pelanggananda/selasa6-5-14/pukul21.00

http://kantorkita.web.id/pentingnya-suarakonsumen-untuk-usaha-anda.html/se lasa6-5-14/pukul21.19 